his sons. An original portrait has also been discovered painted between 1795 and 1799 . $A$ propos of the family of Lamarck, I noticed that the library of the Institute has preserved one. of the annonces sent out by Lamarck on the occasion of the wedding of his son, the engineer, Auguste de Lamarck; and that, in another file, a nephew, Auguste de Longschamps, is mentioned (1825) as having been given the privileges of the library. The archives of the Institute, however, I am sorry to say, fail to show the unpublished portion of Cuvier's éloge of Lamarck: this we hope may still be forthcoming among the extensive papers of Cuvier which the library has recently acquired. The missing portion of the éloge, it need hardly be mentioned, is of special interest, since it will probably throw light on a side of Lamarck's life and work which must to no little degree have been responsible for his neglect. For the rest I may quote an explanation of the contemporary lack of appreciation of Lamarck which was made by an eminent professor at the Jardin. "Lamarck," he said, "was found to be lamentably weak in the facts upon which he based his theories, geological, chemical and meteorological: and as an immediate result his views in these fields came in course of time to be regarded as chimerical. Was it not natural, therefore, that both his friends and foes should query whether his evolutionary doctrines were better founded? His methods were thus known to be in strong contrast to those of Cuvier, who, whatever were his limitations, had at least a thoroughly modern spirit in his laborious quest for facts with which to test the relation between cause and effect."

A final item is the installation in the Jardin des Plantes of a Lamarckian museum. This has been brought together during the past year by Professor Joubin and placed appropriately in a room adjoining the malacological collection. It aims to include all specimens which are known to have passed through the hands of Lamarck. The identification of this material, which thus far consists entirely of invertebrates, has proven by no means an easy task, for original labels have frequently been displaced or lost, or covered by later labels. It is to be hoped that the authorities may see fit to extend the scope of the museum in many directions.

B. D.

\section{THE TOTAL ECLIPSE OF SEPTEMBER 9, 1904.}

A total eclipse of the sun occurred on September 9, 1904. The shadow path crossed the central Pacific Ocean from west to east without touching known land, except that it reached the coast of northern Chile six or eight minutes before sunset. Astronomer William $\mathrm{H}$. Wright, in charge of the D. O. Mills expedition from the Lick Observatory to Santiago, Chile, states that Dr. Obrecht, director of the National Observatory of Chile, established an observing station at Taltal, but that the sky was cloudy at the time of totality. At Santiago the sun set, partially eclipsed, on a fine horizon. W. W. C.

Lick ObServatory, University of California, November 29, 1904.

\section{THE AMERICAN SOCIETY OF VERTEBRATE PALEONTOLOGISTS.}

The American Society of Vertebrate Paleontologists will hold its second annual meeting in Philadelphia on December 28 to 30. By arrangement with the American Association for the Advancement of Science the meetings of the Zoological Section of the association will be held in the mornings while those of the Paleontological Society will be held in the afternoons at the same time that the Zoological Society is in session. Thus it is understood that the meetings of both societies will not conflict with the morning sessions of the American Association section, in which the papers will be of a general character.

For the Paleontological Society papers are already promised by Messrs. Osborn, Scott, Sinclair, Matthew, Merriam, Loomis and Hay. The presidential address by Professor Osborn will be entitled 'Ten Years' Progress in Mammalian Paleontology,' including a résumé of the principal discoveries of the past ten years and their bearing upon present and future problems. There will also be a discussion on the evolution and classification of the Reptilia, 